\title{
Other Multiple Areas
}

National Cancer Institute

\section{Source}

National Cancer Institute. Other Multiple Areas. NCI Thesaurus. Code C18916.

Used when the correct precoordinated combinations of areas is not listed. 